\title{
Perceptions of the role and contribution of HUMAN RESOURCE PRACTITIONERS IN A GLOBAL PETROCHEMICAL COMPANY
}

\author{
H PIETERSE and S ROTHMANN
}

School of Behavioural Sciences, North-West University, Vanderbijlpark

\begin{abstract}
The value-adding contribution of human resources departments in organisations has often been questioned. The objective of this study was to compare the perceptions of human resource practitioners in a global petrochemical company concerning expected and real contributions to business performance with those of their internal clients. The results showed that human resource practitioners and their line customers agree on the importance of the human resources roles that enable business performance, indicating that human resource practitioners have a good understanding of their job requirements. However, both human resource practitioners and their line customers perceive the performance of human resource practitioners to be average, which is lower than the expected level of performance as indicated by importance scales.
\end{abstract}

Abstract

JEL 015, P47

\section{1 \\ Introduction}

The human resource function fulfils an important role by contributing to business performance. According to Ulrich (1997), globalisation and the influence of technological development on time and communication, new competitive challenges and fast-changing corporate cultures have changed the agenda for human resource professionals from that of a primarily transactional to a value-adding approach. Business managers have to be able to manage the performance of employees from different national backgrounds and within fast-changing corporate cultures (Addison, 2003). This has changed the competencies and roles organisations expect human resource practitioners to fulfil (Othman, AbdulGhani \& Arshad, 2001). The ability of human resource practitioners to adapt to changing environments has become particularly important.
Panayotopoulou and Papalexandris (2004) argue that changes in modern corporate environments have shifted the human resource emphasis from a "management practices" orientation to a "management deliverables" orientation. According to this view, the focus has shifted to organisational growth, organisational outcomes and business performance, firstly by identifying the relevant and important human resource activities, and secondly by finding evidence of practitioners' contribution to individual and company performance to provide a competitive advantage. Because of recent developments, human resource practitioners now have to contribute to the resolution of real business issues by focussing on the business value chain, profitability through increased revenue and decreased costs, organisational capability, change readiness and intellectual capital attraction and retention.

The value adding contribution of the human resources departments in the organisation where 
this study was undertaken has also been under the spotlight for a number of years. The business is expanding continuously, both in South Africa and globally, and discussions with business managers create the impression that human resource practitioners are not adding value according to expectations. It appears that every business manager has a different perception of what the primary role of human resource practitioners should be. It also became evident that business managers expect a higher level of performance from human resource practitioners than the one they currently deliver. Discussions with human resource practitioners confirmed this opinion. The situation raises concern in terms of the wellness of human resource practitioners in the global petrochemical industry, which is supported by high utilisation of employee assistance programmes offered by human resource personnel.

Based on the above description of the research problem, the question arises as to which are the most important human resource competencies, and what the perceived level of performance of human resource practitioners on these competencies in a South African petrochemical industry is. More specifically, it is unclear whether the line managers and human resource practitioners in this particular South African petrochemical company perceive human resource competencies as important business enablers, as suggested by recent literature. A further question arises as to whether managers and human resource practitioners in this particular industry currently perceive their human resource practitioners to be sufficiently competent in respect of these business-enabling human resources roles. According to Ulrich (1997), human resource practitioners should fulfil four important roles: strategic partner, administrative expert, employee champion and change agent to add value to and to deliver results in the modern global business environment. There have been no studies on the importance of these roles for managers and human resource practitioners. In addition, it remains unclear whether human resource practitioners perform well in these roles. As not much is known about the psychometric properties of the Human Resource Role-
Assessment Survey (Ulrich, 1997), it is also necessary to confirm the factor structure and internal consistency of this instrument for purposes of this study.

\section{2}

\section{Roles and perceptions of the human resource function}

Human resource management involves a series of integrated decisions on the employment relationship. These decisions influence the effectiveness of employees and the organisation (Milkovich \& Boudreau, 2000). In most organisations, two groups perform human resource management activities - human resource practitioners and line managers. Line managers are organisational managers and supervisors are responsible for the effective utilisation of the resources at their disposal (including human resources). Human resource practitioners render a service to line managers, providing expert advice and ensuring that they adhere to policies on human resource management.

\subsection{Roles of the human resource function}

Ulrich's (1997) four roles for human resource practitioners, mentioned above, strategic partner, administrative support, employee champion, and change agent, will now be considered.

Strategic partner. Changing work environments and corporate cultures are forcing human resource practitioners and line managers to work together to support business strategies, emphasising the need for a different set of organisational enabling competencies for human resource practitioners (Treen, 2000; Ulrich, 1997). Strategic partnering between line managers and human resource practitioners involves the alignment of human resource activities and initiatives with the global business strategy.

The human resource role has evolved from that of performing administrative and transactional activities to manufacturing, to services and lately to information, with increased emphasis on knowledge of workers. The value of the latter 
to the organisation can be expressed in financial terms, as they are responsible for putting company values into practice and achieving organisational strategy (Beatty, Huselid \& Schneier, 2003). It is evident that line customers expect a movement away from the traditional focus on recruitment, training, appraising and rewarding towards a business partnering role, where human resource practitioners and operation managers are equally responsible for business results and competitiveness (Ulrich, 1997).

Gratton (2000) suggested that human resource practitioners should also be able to evaluate the accuracy of perceptions of the current reality and build a business case for people in the organisation. Worsfold (1999) refers to distinctive people-management models focusing on the integration of human resource policies and that of human resource and business strategies as "strong" human resource models. Such models have both a soft component that focuses on interventions to improve commitment and development and a hard component that focuses on the optimal utilisation of people (productivity improvement). Modern human resource practitioners should contribute to the business value chain as both individual employees and consultants, influencing the performance and commitment of employees. The involvement of human resource practitioners in budgets and mainstream decision-making also indicates a trend to integrate human resource and business strategies (Worsfold, 1999).

Human resource practitioners tend to aspire to work closely with business managers to achieve business goals, occasionally without a proper understanding of what the term "strategic partner" actually means (King, 2002). However, changing the priorities of line managers implies that human resource practitioners also have to change what they do if they are to influence the mindset, competencies and behaviour of employees and be seen by line managers as strategic business partners. It is therefore accepted for purposes of this research that strategic partnering is an important component of human resource practitioner performance.

Administrative expert. The human resource practitioner in his or her role as administrative expert has to provide quality service at the lowest possible cost to the organisation. The importance of meaningfulness and the alignment of people processes remain a significant component of human resource practitioner competence (Gratton, 2000). In this context, people processes refers to processes in the traditional human resource value chain, i.e. recruitment, selection, placement, remuneration and benefits, training and development, employee relations and termination of the employment agreement. Human resource practitioners are expected to develop recruitment and selection strategies that will source and retain competence and intellectual property (Childre, Cryer \& Cooper, 2000) to sustain competitive advantage (Lawler \& Finegold, 2000).

Human resources practitioners also have to develop remuneration and training systems that reinforce the organisation's value systems. Treen (2000) concurs, arguing that human resource practitioners have an ideal vantage point that makes it possible to support managers in strategy execution. Line managers expect human resource practitioners to develop and align processes, skills and competencies to facilitate the realisation of long-term business strategies. Haynes and Freyer (2000) refer to studies carried out in the mid- and late-1990s that indicate positive relationships between human resource management practices and organisational performance. The studies suggest that competence and commitment can be increased by effective training, communication, empowerment and performance management systems. However, very few useful theories have resulted from such studies. It might be a more important challenge for human resource practitioners to find methods of increasing and maintaining employee commitment (Foote \& Robinson, 1999; Swailes, 2004). Contemporary human resource practitioners tend to overemphasise their strategic partnering role, occasionally neglecting the administrative and process support necessary to support strategy execution.

Employee champion. Championing employees is a very important human resource practitioner role. It requires practitioners to be cognisant of employees' interests and protect them during 
the process of change in the organisation. Human resource practitioners often support the philosophy of "people business is line business", suggesting that line management at least needs to be involved in all human resource management practices to ensure business performance (Vermeulen, 2003). Human resource practitioners should demonstrate respect for people and should be seen as fair (Snelgar \& Potgieter, 2003), decisive and honest whenever people decisions on matters like transformation, retrenchment and employment equity have to be made. The human resources department also has an important role to play in the integration of management ethics with human resource practices in South Africa (Van Zyl, 2002).

Many organisations have started employee assistance programmes (EAPs) with a view to addressing work-wellness issues, but these have had different levels of success. Negative feedback on EAPs is for the most part related to the inability of outsourced service providers to report promptly on wellness trends in the organisation. This raises the question as to whether EAPs should be sourced through internal human resource practitioners or external consultants. Research indicates that it is appropriate for companies with fewer than 200 employees to outsource their EAPs, but that confidentiality and other issues make it more attractive for larger organisations to provide such a service using internal human resource functions (Gammie, 1997). However, companies often outsource such programmes because internal human resource practitioners do not seem to have the competence or ability to provide the required employee support. The fact that employee wellness and assistance programmes are behaviourally based implies, in terms of this research, that human resource practitioners can influence the prosperity of the organisation by providing effective personal support to employees. Cost savings through prevention of incidents, absenteeism and litigation seem to bring the greatest benefits to organisations in this regard.

Change agent. The role of change agent is about supporting the change and transition of the organisation in the area of the human capital.
The role of human resources is to support change activities and to ensure the capacity for the changes. According to research done by the American Management Association, 84 per cent of American companies were busy with and/or planning major impending change processes at the beginning of the millennium (Weber \& Weber, 2001). Change has become the norm, and training and development programmes must facilitate relearning and re-envisioning (Treen, 2000). This should be designed to assist employees in "unlearning" redundant skills and knowledge and in adapting to shorter cycle times to facilitate fundamental and enduring change through real transformation (Ulrich, 1997). It has become necessary to manage organisational change as a continuous and dynamic process (Ashton, 1996). Ignoring the "human ingredient" will probably lead to failure in transformation and change processes (Bramson, 2000).

\subsection{Perceptions of human resource contribution and priorities}

Critical performance indicators and competency models for human resources departments are no longer determined independently by human resource directors, but by business managers with a proper understanding of human behaviour (Fulmer, 2002). This is probably the reason why some successful companies are appointing successful general managers in human resource management positions. Becker, Huselid and Ulrich (2001) maintain that business managers are sceptical about the ability of human resource practitioners to influence the bottom-line success of the organisation, mainly because the contributions of human resources departments in this respect are difficult to measure. The movement from an employee support focus to a business management focus has occasionally resulted in the sidelining of ethical issues, which influences the credibility of the human resource function (Foote \& Robinson, 1999). King reported that change management support from the human resources department is seen as even more important than strategic partnering (King, 2002). Modern business managers have also realised the necessity for employee 
health and wellness initiatives, acknowledging that a relationship exists between employee wellness and business results. However, very few companies measure whether such initiatives actually have any impact on work performance (Hacker \& Doolan, 2002).

King (2002) believes that there is a high expectation among business managers for human resource practitioners to focus primarily on transactional and administrative support and other traditional human resource processes, such as recruitment and selection rather than strategic business partnering.

\subsection{Influence of human resource practices on organisational effectiveness}

A limited number of studies describing human resource practitioners' perception of their actual contribution to business success could be traced. Alcker and McHugh (2000: 316) concluded that human resource practitioners might feel that, although they "should be driven by issues of strategic, financial and quality control, they are in effect still wedded to residual roles that involve welfare/counselling". According to Vermeulen (2003), few studies have investigated whether the human resource function has indeed made the transition to fulfil the roles that the changes of the $21^{\text {st }}$ century require. Othman et al. (2001) reported that only 10 per cent to 35 per cent of human resource managers have the ability and competencies needed to create a business-focused approach in human resource activities.

Literature shows contradictory results in terms of the influence of human resource practices on organisational effectiveness (Beatty et al., 2003; Christensen Hughes, 2002; Richard \& Johnson, 2001). Over the past 25 years, the primary focus of human resource functions has shifted from an employee welfare focus to a business management focus, resulting in increased ambiguity about the role of human resource practitioners (Foote \& Robinson, 1999). While companies seem equally committed to quality, different levels of commitment to human resource management are evident (Worsfold, 1999).
Buyens and de Vos (2001) in Belgium used the Human Resource Role-Assessment Survey in their research to determine whether non-human resource functions and senior executives support the importance of the human resources department's role as strategic business partner (Ulrich, 1997). The results showed that, although the human resource fraternity aspires to become a strategic business partner, business functions and senior executives occasionally continue to hold a traditional view emphasising the people-management role of human resource practitioners as custodian of recruitment, learning and development and remuneration activities (Christensen Hughes, 2002). The results indicated further that there is a stronger need in organisations for human resource practitioners to focus on enabling transformation and change and administrative support. Such findings contradict those of Wright, Geroy, and MacPhee (2000) that human resource practitioners direct behaviour to the accomplishment of the organisation's mission and goals, and that human resources departments play a critical role in global strategy. It seems that certain top managers expect human resources departments to play some strategic role in the business, but that they do not consider it necessary to involve human resource practitioners in strategy development (Buyens \& de Vos, 2001; Othman et al., 2001).

Human resource practices influence employee behaviour, which in turn both aids organisational effectiveness and provides a competitive advantage (Buyens \& de Vos, 2001). This implies a direct relationship between human resource practitioner effectiveness and organisational level outcomes, as indicated, for example, in research by Aycan (2001), who maintains that human resource management has been instrumental in the competitiveness of Turkish companies since 1986, especially those in which every employee is considered to be a strategic partner to be treated as such. Bramson (2000) views the assessment of human capital during mergers and acquisitions as an asset that will not be found in any balance sheet. According to this view, human resource practitioners can help prevent critically important employees from leaving when mergers take place. Human 
resource practitioners also play a crucial role in the merger/acquisition decision through the evaluation of culture compatibility and culture alignment (Horwitz et al., 2002). Research by Haynes and Fryer (2000) indicates that human resource management practices can increase customer satisfaction and financial performance. On the other hand, Worsfold (1999) found little proof that human resource practices have any influence on financial performance, productivity or product quality. Panayotopoulou and Papalexandris (2004) showed that human resource management has a more significant effect on organisational growth and innovation than on the financial performance of companies. It seems that objective measures of human resource practitioner performance are unreliable, mostly because of methodological weaknesses and response bias. However, strong relationships exist between employee perceptions of human resource practices and customer satisfaction, indicating that human resource practices have a direct effect on service cultures (Worsfold, 1999).

A variety of human resource management models can be found in current literature (Panayotopoulou \& Papalexandris, 2004). Human relations models emphasise concern for people as an indicator of successful human resource management models, whereas open systems models define success as flexibility and change readiness. These two models link positively to performance. Predictability and process efficiency indicate success in open systems models as a third option, whereas rational goal models focus on real business results. However, there are very few available guidelines on how to choose a human resource management model that will facilitate business success during specific life cycles in organisations.

The ambiguity and contradictory findings referred to in these studies have certain important implications for this research. They emphasise the need for empirical research to determine the relationship between the roles of the human resource function and performance (Christensen Hughes, 2002). The findings also indicate that perceptions play an important role in the evaluation of human resource practitioner performance. According to Alcker and McHugh (2000), such contradictions also indicate the need to verify the validity and reliability of the HRRAS (Ulrich, 1997) as an instrument for measuring human resource practitioner performance.

\subsection{Implications for human resource practitioners in the South African petrochemical industry}

Human resource functions in modern global organisations have to adapt human resource strategies and practices according to the life cycle stage of the organisation - formation, growth, maturity or decline (Christensen Hughes, 2002). This means that human resource practitioners should possess the strategic business skills necessary if they are to contextualise the stage the business is in before deciding on a human resource strategy. There should also be a continuous process of learning new human resource methods and philosophies while unlearning the old. According to Beatty, Huselid, and Schneier (2003), human resource practitioners ought continuously to measure their current performance in terms of what is needed to achieve business goals before deciding on how to change their focus to make the company more successful. This implies constant measurement and adaptation of human resource focus and priorities to correlate with the phases of the organisational life cycle and the strategic shifts it necessitates. It also means that there should be caution when benchmarking human resource activities against those of other organisations. If human resource practitioners are not aware that such organisations are in different life-cycle stages, this could lead to irrelevant human resource focus and activities. In certain companies, it might even be necessary to consider different human resource focuses and strategies for different business units.

South African organisations are facing a phase of transition and instability similar to that faced by many other global organisations, which probably makes it difficult for local employers to integrate human resource issues with business strategy. This means that South African human resource practitioners, too, should be able to 
adapt to change (Struwig, Smith \& Venter, 2003), and to develop competencies to facilitate and support transformational change (Anderson \& Anderson, 2001).

The "brain drain" of highly skilled people because of emigration, internal migration, murder and HIV and related illnesses negatively affects the ability of South African organisations to compete in the global market. An influx of unskilled people is further eroding the skilled workforce (du Preez, 2002). Strategic longterm people-planning and talent management is necessary if South African organisations are going to attract and retain competent and committed people to ensure business continuity and competitiveness. Employers in South Africa need human resource practitioners who are able to integrate human resource practices and business strategies to overcome such threats.

Empirical support exists suggesting a positive relationship between superior financial performance and participative work systems focused on high employee performance and commitment in petrochemical companies where human resource strategies are aimed at improving employee commitment and trust (Christensen Hughes, 2002). However, Birken (2005) warns South African businesses against "one-size-fitsall-management" fads, which he considers a marketing stunt offered by consultants who do not know or appreciate the organisation's actual needs, style and culture. Such interventions are usually focused on a particular dimension in the organisation and do not consider the entire organisation. According to this view, internal human resource consultants should be more effective than external consultants in assisting line management to address strategic issues.

It should also be borne in mind that the South African labour market is governed by a set of complicated and integrated legislation, which requires human resource practitioners to continually interpret and advise line managers on people practices and people strategies (Vermeulen, 2003).

Gammie (1997) has highlighted the positive effect of employee wellness programmes on organisational performance. These programmes reduce stress and improve general employee wellness and performance in the oil and gas industry. Gammie (1997) points out that, although statistics occasionally do not support employee claims concerning the negative impact of work factors (e.g. number of divorce cases), perceptions of such negative impacts are obvious stressors that influence employee wellness, safety and quality of performance. Human resources departments have an important role to play in the unique petrochemical work environment in explaining to management the apparent contradiction between such statistics and employee wellness.

The literature reviewed for the purposes of this study indicates support for the human resources roles suggested by Ulrich (1997). However, some trends are of concern. Firstly, there is pressure on human resource practitioners to deliver a variety of specialised human resource services to contribute to business success in modern organisations. However, there are apparently contradictory views on the priority of the different human resources roles. This might indicate excessive and uncertain job demands that would in all likelihood cause distress (Rothmann \& Rothmann, 2006) for human resource practitioners. These would make it difficult for them to perform according to customer expectations and could have a negative impact on the wellness of human resource practitioners.

\section{3}

\section{Study objective and hypotheses}

The objective of this study was to compare the perceptions of expected and actual contributions of human resource practitioners to business performance in a global petrochemical company.

The following hypotheses were set for this study:

Hypothesis 1: Human resource practitioners do not perceive the differences between the importance of the four roles they fulfil (i.e. strategic partner, administrative expert, employee champion and change agent) and their own performance in these roles.

Hypothesis 2: Line managers do not perceive the differences between the importance of the four roles of human resource practitioners 
(i.e. strategic partner, administrative expert, employee champion and change agent) and their performance in these roles.

Hypothesis 3: Line managers and human resource practitioners do not differ regarding their perceptions of the importance of and performance in the four roles of human resource practitioners (i.e. strategic partner, administrative expert, employee champion and change agent).

\section{4}

\section{Method}

\subsection{Research design}

This study was exploratory and descriptive (Mouton \& Marais, 1990). A cross-sectional survey design was used to investigate demonstrable relationships between dependent and independent variables at a specific point in time.

\subsection{Participants}

The study was conducted in a petrochemical company operating in South Africa and a number of other countries in Africa, Europe and the United States. This research targets employees who are considered to be in the best position to provide information on current and expected strategic human resource-related competencies, performance and work experiences.

The sample selected for this research includes all 709 human resource generalists, managers and specialists in this organisation, as well as the most senior functional managers to whom they are rendering a human resource service. Secretarial human resource staff are excluded and only those administrative staff who are currently managing human resource administration functions are included in the sample. A total of 1418 questionnaires were distributed and 195 usable completed questionnaires were returned. 128 responses from human resource personnel and 67 from functional line managers were received. This represents a response ratio of 13,8 per cent. Table 1 and Table 2 show the characteristics of the participants.

\section{Table 1}

Participant characteristics (human resource practitioners)

\begin{tabular}{|c|c|c|c|}
\hline Item & Category & Frequency & Percentage \\
\hline \multirow[t]{5}{*}{ Age } & Younger than 36 years & 26 & 20,3 \\
\hline & $36-40$ years & 20 & 15,6 \\
\hline & $41-45$ years & 25 & 19,5 \\
\hline & $46-50$ years & 33 & 25,8 \\
\hline & Older than 50 years & 24 & 18,8 \\
\hline \multirow[t]{2}{*}{ Gender } & Male & 75 & 58,6 \\
\hline & Female & 53 & 41,4 \\
\hline \multirow[t]{3}{*}{ Marital status } & Single & 7 & 5,5 \\
\hline & Married & 107 & 83,6 \\
\hline & $\begin{array}{c}\text { Separated/divorced/ } \\
\text { widower }\end{array}$ & 14 & 10,9 \\
\hline \multirow[t]{6}{*}{ Years with current employer } & Less than 5 years & 21 & 16,4 \\
\hline & $5-9$ years & 29 & 22,7 \\
\hline & $10-14$ years & 20 & 15,6 \\
\hline & $15-19$ years & 20 & 15,6 \\
\hline & $20-24$ years & 18 & 14,1 \\
\hline & More than 24 years & 20 & 15,6 \\
\hline
\end{tabular}




\begin{tabular}{|l|c|c|c|}
\hline Current position & Non-managerial & 30 & 23,4 \\
& First-line supervision & 51 & 39,8 \\
& Middle Management & 32 & 25,0 \\
& Senior management & 13 & 10,2 \\
& Top management & 2 & 1,6 \\
\hline Years on current job level & Less than one year & 15 & 11,7 \\
& $1-2$ years & 41 & 32,0 \\
& $3-4$ years & 35 & 27,4 \\
& $5-6$ years & 15 & 11,7 \\
& Longer than 6 years & 22 & 17,2 \\
\hline \multirow{2}{*}{ Qualifications } & Grade 12 or lower & 24 & 18,8 \\
& $1-2$ year diploma & 12 & 9,4 \\
& 3 year diploma / degree & 51 & 39,8 \\
& Post-graduate & 41 & 32,0 \\
\hline
\end{tabular}

Most of the human resource participants are married ( 83,6 per cent) and have been employed in this specific organisation for more than ten years $(60,9$ per cent). This might explain the relatively high number of human resource practitioners who are older than 36 years $(79,7$ per cent). Only 28,9 per cent of the human resource practitioners who participated in the research have been on their current job level for longer than five years. The organisation frequently promotes its human resource practitioners and sufficient career opportunities are available to prevent frustration with career progress. Only 23,4 per cent of the human resource practitioners who responded are not at the supervisory or management level. This supports the aim to target employees who are in the best position to provide information on current and expected strategic human resourcerelated competencies, performance and work experiences.

Table 2 indicates that only 14,9 per cent of the functional line managers who responded are not in at least first-line management positions. This indicates that the survey was successful in targeting the more senior internal line customers to whom human resource practitioners in this organisation are rendering a human resource service.

Table 2

Line customers' job levels

\begin{tabular}{|l|l|c|c|}
\hline & \multicolumn{1}{|c|}{ Category } & Frequency & Percentage \\
\hline Job levels of functional managers & Non-managerial & 10 & 14,9 \\
& First-line supervision & 7 & 10,4 \\
& Middle Management & 18 & 26,9 \\
& Senior management & 24 & 35,9 \\
& Top management & 8 & 11,9 \\
\hline
\end{tabular}

\subsection{Measuring instrument}

Ulrich (1997) developed the Human Resource Role-Assessment Survey (HRRAS)) to explore the roles human resource practitioners are playing in organisations. Roles are presented in the form of statements, for instance human resources help the organisation achieve, inter alia, business goals. They also participate in delivering human resource processes. Items are scored on a five-point frequency rating scale that indicates the extent to which the respondent agrees with the statement, varying from 1 
(low) to 5 (high). The instrument has been adapted for purposes of this study to include a rating of the level of importance of each subscale (Strategic Partnering, Administrative Expertise, Employee Support and Change Management) in the questionnaire. The revised instrument measures the perceived business enabling value of human resource practitioners' competencies/roles, as well as the perceived quality of performance of human resource practitioners on each subscale (including Strategic Partnering, Administrative Expertise, Employee Support, and Change Management). Cronbach alpha coefficients reported in this study varied between 0,89 (perceived importance of human resources' responsibility to provide administrative support) and 0,96 (perceived level of human resources' performance as change agents).

\subsection{Statistical analysis}

The statistical analysis was carried out with SPSS (SPSS Inc., 2003). Only one previous study was found which made use of the Human Resource Role-Assessment Survey (Buyens \& de Vos,
2001). The researchers used confirmatory factor analysis to investigate the factorial model of the Human Resource Role-Assessment Survey. Principal component analysis included 40 items of the HRRAS for a sample of 128 human resource practitioner responses. Cronbach alpha coefficients were used to assess the internal consistency of the HRRAS.

Secondly, descriptive statistics (e.g. means and standard deviations) and inferential statistics were applied to analyse the data. Independent t-tests (two-tailed) were used to determine whether differences exist between perceptions of human resource practitioners and their customers regarding the importance and current quality of human resource performance on each of the subscales.

\section{5}

\section{Results}

The four subscales of the Human Resource Role-Assessment Survey (HRRAS) were subjected to confirmatory factor analysis (see Table 3).

Table 3

Confirmatory factor analysis of the Human Resource Role-Assessment Survey

\begin{tabular}{|l|c|c|}
\hline \multicolumn{1}{|c|}{ Factor } & \% Variance explained & $\alpha$ \\
\hline Factor 1: Strategic partner & 54,15 & 0,90 \\
\hline Factor 2: Administrative expert & 50,84 & 0,89 \\
\hline Factor 3: Employee champion & 63,43 & 0,93 \\
\hline Factor 4: Change agent & 61,51 & 0,93 \\
\hline
\end{tabular}

The results, as indicated in Table 3 , confirm that the original factorial structure of the HRRAS can be retained. The proportion of variance accounted for by the factors, as suggested by Ulrich (1997), varies between 50,84 per cent
(Administrative expert) and 63,43 per cent (Employee champion).

Dependent $t$-test (two-tailed) results for human resource practitioner perceptions are displayed in Table 4. 


\section{Table 4}

Paired samples statistics and t-test results for the human resource group $(\mathrm{N}=128)$

\begin{tabular}{|l|c|c|c|c|c|c|c|}
\hline \multirow{2}{*}{\multicolumn{1}{c|}{ Items }} & \multicolumn{2}{|c|}{ Importance } & \multicolumn{2}{c|}{ Performance } & \multicolumn{2}{|c|}{} \\
\cline { 2 - 7 } & Mean & SD & Mean & SD & t & p & d \\
\hline Strategic partner & 4,52 & 0,51 & 3,39 & 0,69 & 16,35 & 0,00 & 1,63 \\
\hline Administrative expert & 4,24 & 0,57 & 3,50 & 0,69 & 10,55 & 0,00 & 1,07 \\
\hline Employee champion & 4,32 & 0,63 & 3,31 & 0,83 & 11,40 & 0,00 & 1,22 \\
\hline Change agent & 4,49 & 0,57 & 3,28 & 0,82 & 14,80 & 0,00 & 1,47 \\
\hline
\end{tabular}

* $\quad \mathrm{p}<0,01$

$+\quad d>0,80$ (practically significant, large effect)

Analysis of Table 4 reveals that human resource practitioners perceive their performance as strategic partners (Mean $=3,39 ; S D=0,69)$ to be significantly lower than their own perceived importance of this role $($ Mean $=4,52 ; S D=$ $0,51 ; t=16,35 ; p<0,01)$. Similar significant and statistically meaningful results were found in terms of the difference between perceived performance as administrative experts $(t=10,55$; $p<0,01)$, employee champions $(t=11,40 ; p<$ $0,01)$ and change agents $(t=14,80 ; p<0,01)$ and the perceived importance of these roles. These findings were practically significant (large effect, $d>0,80)$. Hypothesis 1 is therefore rejected.

Dependent $t$-test results for line customer perceptions are displayed in Table 5.

\section{Table 5}

Paired samples statistics and t-test results for the line customers group $(N=67)$

\begin{tabular}{|l|c|c|c|c|c|c|c|}
\hline \multirow{2}{*}{\multicolumn{1}{c}{ Items }} & \multicolumn{2}{|c|}{ Importance } & \multicolumn{2}{c|}{ Performance } & \multirow{2}{*}{} & \multirow{2}{*}{ d } \\
\cline { 2 - 7 } & Mean & SD & Mean & SD & t & P & d \\
\hline Strategic partner & 4,39 & 0,55 & 3,28 & 0,75 & 12,01 & $0,00^{*}$ & $1,49+$ \\
\hline Administrative expert & 4,01 & 0,61 & 3,37 & 0,70 & 5,61 & $0,00 *$ & $0,92+$ \\
\hline Employee champion & 4,15 & 0,61 & 3,28 & 0,84 & 7,44 & $0,00^{*}$ & $1,04+$ \\
\hline Change agent & 4,43 & 0,56 & 3,10 & 0,91 & 10,58 & $0,00^{*}$ & $1,47+$ \\
\hline
\end{tabular}

* $\quad \mathrm{p}<0,01$

$+\quad d>0,80$ (practically significant, large effect)

Analysis of Table 5 reveals that line customers perceive the performance of human resource practitioners as strategic partners (Mean $=$ $3,28 ; S D=0,75)$ to be significantly lower than the perceived importance of this role (Mean $=$ 4,39; $S D=0,55 ; t=12,01 ; p<0,01)$. Similar significant and statistically meaningful results were found in terms of the difference between perceived performance as administrative expert $(t=5,61 ; p<0,01)$, employee champion $(t=$
$7,44 ; p<0,01)$ and change agent $(t=10,58$; $p<0,01)$ and the perceived importance of these roles. All the effect sizes were large $(d>$ 0,80 ), indicating the practical significance of the findings. Based on these results, Hypothesis 2 is rejected.

Independent $t$-test (two-tailed) results for the perceptions of human resource practitioners and those of line customers are compared in Table 6. 
Table 6

Descriptive statistics and t-test results for the combined group

\begin{tabular}{|c|c|c|c|c|c|c|c|}
\hline \multirow[b]{2}{*}{ Items } & \multicolumn{2}{|c|}{$\begin{array}{l}\text { Human resources } \\
\qquad(\mathrm{N}=128)\end{array}$} & \multicolumn{2}{|c|}{$\begin{array}{c}\text { Line } \\
\text { customers } \\
(\mathrm{N}=67)\end{array}$} & \multirow[b]{2}{*}{$\mathbf{t}$} & \multirow[b]{2}{*}{$\mathbf{p}$} & \multirow[b]{2}{*}{ d } \\
\hline & Mean & SD & Mean & SD & & & \\
\hline Strategic partner importance & 4,51 & 0,51 & 4,39 & 0,55 & 1,46 & 0,15 & 0,22 \\
\hline Administrative expert importance & 4,24 & 0,57 & 4,01 & 0,61 & 2,58 & $0,01^{*}$ & 0,38 \\
\hline Employee champion importance & 4,31 & 0,63 & 4,15 & 0,61 & 1,67 & 0,10 & 0,25 \\
\hline Change agent importance & 4,48 & 0,57 & 4,43 & 0,56 & 0,61 & 0,54 & 0,09 \\
\hline Strategic partner performance & 3,39 & 0,69 & 3,28 & 0,75 & 1,05 & 0,30 & 0,16 \\
\hline Administrative expert performance & 3,50 & 0,69 & 3,37 & 0,70 & 1,22 & 0,23 & 0,18 \\
\hline Employee champion performance & 3,31 & 0,83 & 3,28 & 0,84 & 0,19 & 0,85 & 0,03 \\
\hline Change agent performance & 3,28 & 0,82 & 3,10 & 0,91 & 1,42 & 0,16 & 0,20 \\
\hline
\end{tabular}

* Statistically significant: $p<0,05$

$+d>0,80$ (practically significant, large effect)

According to Table 6, there were statistically significant differences between the perceptions of human resource practitioners and those of their line customers in terms of the importance of the administrative expert role. Human resource practitioners perceived this role to be more important $($ Mean $=4,24 ; S D=0,57)$ than did their line customers (Mean $=4,01 ; S D=$ $0,61 ; t=2,58 ; d=0,38)$. Hypothesis 3 is rejected for one role of human resource practitioners, namely that of administrative expert.

\section{6}

\section{Discussion}

The aim of this study was firstly to confirm the validity of the Human Resource RoleAssessment Survey (Ulrich, 1997) and secondly to determine the relationship between the perceptions of functional managers and those of human resource practitioners regarding the importance of human resources roles, as well as the perceived business enabling contribution of human resource activities.

The results of this study confirmed that the original factorial structure of the HRRAS can be retained. It was also found that human resource practitioners perceive their performance as strategic partners to be significantly lower than their own perceived importance of this role. Significant and statistically meaningful results were also found in terms of the difference between perceived performance as administrative experts, employee champions and change agents and the perceived importance of these roles. Human resource practitioners rated the administrative expert role as slightly more important than did their line customers.

The research confirmed the factorial validity of the Human Resource Role-Assessment Survey (Ulrich, 1997) as an instrument to measure perceptions of the importance and current performance of human resource practitioners in the global petrochemical industry. Four factors were confirmed. The first represents the Strategic Partner role of the human resources department, referring primarily to the participation of human resource practitioners in business strategy development and the positioning of the activities of the human resources department to facilitate strategy implementation. The second factor, the Administrative Expert role, refers to the development, implementation and maintenance of functional human resource processes. The third factor, the Employee Champion, refers to the responsibility of human resource 
practitioners to ensure personal support and fairness in human resource processes. The fourth factor, Change Agent, refers to the role of human resource practitioners in facilitating the ever-increasing change initiatives in the organisation.

This study showed that both line managers and human resource practitioners regard the human resources roles suggested by Ulrich (1997) as important. However, contrary to Ulrich's opinion (1997) that there is a shift from the traditional human resources roles to a strategic partnering role, the results of this study showed that all four roles of human resources practitioners are perceived to be almost equally important. Strategic partnering is perceived by both human resource practitioners and line managers as most important, while administrative expertise is perceived by both these groups to be the least important human resource role. The roles of strategic partner, administrative expert, employee champion and change agent can be viewed as critical performance areas and job requirements for human resource practitioners in the global petrochemical organisation where this study was carried out. It also indicates support for the suggestions of Ulrich (1997) that personal development programmes of human resource practitioners should focus on these roles to improve the ability of the human resources department to contribute to business success. Furthermore, it implies that these roles should form part of the selection criteria during recruitment, selection and promotion of human resource practitioners.

As strategic partners, human resource practitioners in the global petrochemical business should align human resource strategies with overall business strategies and provide human resource infrastructure and the capacity to translate such strategies into supportive human resource processes and activities (Worsfold, 1999). This implies that human resource practitioners can use the strategic focus areas stated in the overall business strategies to motivate and prioritise human resource projects and to evaluate the competence and capacity of the human resources department.

Contemporary human resource practitioners in the global petrochemical industry should also take care not to overemphasise their strategic partnering role to the extent that they neglect the administrative expertise necessary for assisting strategy execution. This study indicated that line customers still regard the traditional transactional human resources roles as relevant and valuable contributors to business success.

This results of this study showed that championing employees is an important role for human resource practitioners. This finding confirms the those of Snelgar and Potgieter (2003) and Van Zyl (2002) that both human resource practitioners and their line customers believe that the human resources department can influence the prosperity of the organisation by providing effective personal support through employee wellness assistance programmes.

Human resource practitioners have to assist employees in developing the skills and knowledge necessary for coping with change and to facilitate fundamental transformation and enduring change (Ulrich, 1997). The findings of this study indicate that the change agent role of human resource practitioners is the most important contribution of human resource practitioners to organisational performance.

Although the experience and academic qualifications of human resource practitioners in this organisation seem to be sufficient, both human resource practitioners and their line customers perceive the current performance of human resource practitioners in all the human resources roles as average, which is significantly lower than the expected level of performance indicated by importance scales. The greatest performance gap seems to be the change management role. Human resource practitioners are perceived as performing better as administrative experts than in their other roles.

From the results of this study it can be deduced that human resource practitioners in the global petrochemical industry have sufficient ability and a good enough theoretical understanding of the expected job demands to facilitate a valuable contribution to business success. On the other hand, they find it difficult to deliver at the level that they and their line customers believe is necessary. Misaligned perceptions of the role human resource practitioners are supposed 
to fulfil in this organisation do not seem to be the reason for the perceived performance gap between line managers and human resource practitioners. This might be one cause of distress (Rothmann \& Rothmann, 2006), resulting in the current high utilisation of employee assistance programmes by human resource practitioners in this organisation.

There are a few limitations to this study. First, further investigation of the participant characteristics indicating competence is necessary because this study considered those characteristics that influence only skills and knowledge. Second, this study excluded personal attributes as a third important dimension of competence, e.g. work attitudes identification with work, work dedication and self-confidence. Third, other variables could have distorted perceptions of current performance levels. This organisation uses forced ranking to ensure that performance ratings are normally distributed. Qualitative follow-up interviews with participants revealed a high level of discomfort with the forced ranking philosophy, which could have distorted responses. Fourth, the sample size was a limitation. Only 13,8 per cent of potential respondents completed the questionnaires. Finally, only one organisation was included in this study. Future studies should include representative samples of line managers and human resource practitioners from different organisations. Despite these limitations, it is impossible to ignore the perceived gap between expected and actual performance. Respondents agree that all the human resources roles should be fulfilled on an exceptional level, which gives evidence that human resource practitioners are expected to contribute to organisational effectiveness.

\section{7}

\section{Recommendations}

The petrochemical industry can affect its business performance in the global arena by improving the level of performance of human resource practitioners. Further research in this environment is necessary to investigate possible causes for the perceived performance gap. Human resource practitioners' coping with the challenges of the modern business environment and how that relates to their locus of control, optimism, burnout, engagement, workaholism should be investigated. Future studies should also investigate distress and stress levels in the human resource fraternity, giving specific attention to their effect on perceived performance levels. This could improve our understanding of the causes of wellness problems in human resources departments to enable the design of interventions to improve wellness of human resource practitioners.

The positive correlation between the perceptions of human resource practitioners and line customers regarding the importance of human resources roles probably indicates that job demands are realistic and that interventions to reduce job demands might not be appropriate. Interventions to improve human resource practitioner wellness and performance as well as future research in this organisation should be designed to confirm the actual effect of job resources on human resource practitioner wellness, rather than that of job demands.

\section{References}

ADDISON, R. 2003. The role of culture in performance improvement. HR Future: June: 4-7. ALCKER, L. \& MCHUGH, D. 2000. Human resource maintenance? Organisational rationales for the introduction of employee assistance programmes. Journal of Managerial Psychology, 15: 303-323. ANDERSON, L.A. \& ANDERSON, D. 2001. The change leader's roadmap: how to navigate your organization's transformation. San Francisco, CA: Jossey-Bass/Pfeiffer.

ASHTON, C. 1996. How competencies boost performance. Management Development Review, 9(3): 14-19.

AYCAN, Z. 2001. Human resource management in Turkey: Current issues and future challenges. Industrial Journal of Manpower, 22: 252-260.

BEATTY, R.W., HUSELID, M.A. \& SCHNEIER, C.E. 2003. New HR metrics: Scoring on the business scorecard. Organisational Dynamics, 32: 107-121. BECKER, B.E., HUSELID, M.A. \& ULRICH, D. 2001. The HR scorecard, Boston, MA: Harvard Business School Press.

BIRKEN, M. 2005. Management fads are still with us. Management Today Yearbook, 22.

BRAMSON, R.N. 2000. HR's role in mergers and acquisitions. Training and Development, 4(3): 59-66. 
BUYENS, D. \& DE VOS, A. 2001. Perceptions of the value of the HR function. Human Resources Journal, 2: $70-89$.

CHILDRE, D., CRYER, B. \& COOPER, R.K. 2000. From chaos to coherence: the power to change performance (rev. ed.) Boulder Creek, CA: HeartMath. CHRISTENSEN HUGHES, J.M. 2002. HRM and universalism: Is there one best way? International Journal of Contemporary Hospitality Management, 12: 221-248.

DU PREEZ, J. 2002. The depletion of the human resources pool in South Africa. Acta Commerci, 2: 80-84.

FOOTE, D. \& ROBINSON, I. 1999. The role of the human resources manager: Strategist or conscience of the organisation. Business Ethics: A European Review, 8(2): 88-98

FULMER, W.E. 2002. Human resource management: The right hand of strategy implementation. Human Resource Planning, 12(4): 1-11.

GAMMIE, B. 1997. Employee assistance programmes in the UK oil industry: An examination of current operational practice. Personnel Review, 26: 66-80. GRATTON, L. 2000. Living strategy: putting people at the heart of corporate purpose, London: Prentice Hall. HACKER, S.K. \& DOOLAN, T.L. 2002. Strategies for living: Moving from the balance paradigm. Career Development International, 8: 283-290.

HAYNES, P. \& FRYER, G. 2000. Human resources, service quality and performance: A case study. International Journal of Contemporary Hospitality Management, 12: 240-248.

HORWITZ, F.M., ANDERSSEN, K., BEZUIDENHOUDT, A., COHEN, S., KIRSTEN, F., MOSOEUNYANE, K., SMITH, N., THOLE, K. \& VAN HEERDEN, A. 2002. Due diligence neglected: managing human resources and organisational culture in mergers and acquisitions. South African Journal of Business Management, 33(1): 1-10.

KING, Z. 2002. Belgian research questions managers about their perceptions of the HR role. People Management, 8(5): 59.

LAWLER III, E.E. \& FINEGOLD, D. 2000. Individualising the organization: Past, present, and future. Organizational Dynamics, 29: 202-218. MILKOVICH, G.T. \& BOUDREAU, J.W. 2000. Human resource management ( $8^{\text {th }}$ ed.) Burr Ridge, IL: Irwin.

MOUTON, J. \& MARAIS, H.C. 1990. Basic concepts in the methodology of the social sciences. Pretoria: HSRC.

OTHMAN, R., ABDUL-GHANI, R. \& ARSHAD, R. 2001. Great expectations: CEOs' perception of the performance gap of the HRM function in the Malaysian manufacturing sector. Personnel Review, 30: 61-80.

PANAYOTOPOULOU, L. \& PAPALEXANDRIS, N. 2004. Examining the link between human resources management orientation and firm performance. Personnel Performance, 33: 499-520.

RICHARD, O.C. \& JOHNSON, N.B. 2001. March. Strategic human resource effectiveness and firm performance. International Journal of Human Resource Management, 12: 299-310.

ROTHMANN, S., \& ROTHMANN, J.C. 2006. The South African employee health and wellness survey: User manual, Potchefstroom: North-West University. SNELGAR, R.J., \& POTGIETER, T. 2003. An exploratory study of group adverse impact in recruitment and selection. South African Journal of Economic and Management Sciences, 6, 89-98. SPSS INC. 2003. SPSS 12.0 for Windows, Chicago, IL: Author.

STRUWIG, F.W., SMITH, E.E. \& VENTER, D.J.L. 2003. Organisational training perspectives in a changing South Africa. South African Journal of Economic and Management Sciences, 6: 591-611. SWAILES, S. 2004. Commitment to change: Profiles of commitment and in-role performance. Personnel Review, 33: 187-204.

TREEN, D. 2000. Strategic human resources. Ivey Business Journal, 64(3): 63-67.

ULRICH, D. 1997. Human resource champions, Boston, MA: Harvard Business School Press. VAN ZYL, E. 2002. Role of the human resources function in the development and implementation of an ethical corporate culture. Acta Criminologica, 15(2): 19-25.

VERMEULEN, L. 2003. Line management's involvement in people management: A comparison between South Africa and Australia. South African Journal of Economic and Management Sciences, 6: 529-541.

WEBER, P.S. \& WEBER, J.E. 2001. May. Changes in employee perceptions during organizational change.

Leadership and Organizational Development Journal, 22: 291-300.

WORSFOLD, P. 1999. HRM, performance, commitment and service quality in the hotel industry. International Journal of Contemporary Hospitality Management, 11: 340-348.

WRIGHT, P.C., GEROY, G.D. \& MACPHEE, M. 2000. A human resources model for excellence in global organization performance. Management Decision, 38(1): 36-42. 